\title{
NGHIÊN CƯ'U XÂY DỬNG MÔ HÌNH CUNG CẤP DỊCH VỤ, SẢN PHẨM ĐO ĐẠC BẢN ĐỒ TRÊN MÔI TRƯỜNG MẠNG
}

\author{
ThS. NGUYẼ̃N VĂN TUÂN \\ Cục Đo đạc và Bản đồ Việt Nam
}

\section{Tóm tắt:}

Bài báo mô tả kết quả nghiên cứu về hình thức cung cấp dữ liệu đang được thực hiện tại Cục Đo đạc và Bản đồ Việt Nam. Nghiên cứu xây dựng mô hình cung cấp dịch vụ, sản phẩm đo đạc bản đồ thông qua mạng internet, cho phép người sử dụng có thể tiếp cận dữ liệu một cách nhanh chóng và tiện lợi hơn.

\section{1. Đặt vấn đề}

Trung tâm Thông tin Tư liệu đo đạc và bản đồ là đơn vị sự nghiệp trực thuộc Cục Đo đạc và Bản đồ, Bộ Tài nguyên và Môi trường; có chức năng quản lý, lưu trữ, xử lý và cung cấp thông tin - tư liệu đo đạc và bản đồ, bao gồm: Tư liệu trắc địa, tư liệu bản đồ, tư liệu ảnh, tư liệu địa danh và cơ sở dữ liệu nền địa lý. Hiện nay, công tác quản lý, khai thác và cung cấp thông tin dữ liệu đo đạc bản đồ với các phương pháp và công nghệ cũ gặp rất nhiều khó khăn, chưa thực sự thuận tiện cho khách hàng. Vì vậy cần có một mô hình cung cấp dịch vụ, sản phẩm đo đạc bản đồ hiệu quả hơn, giúp cho khách hàng có thể tiếp cận dữ liệu một cách nhanh chóng và thuận tiện.

Việc nghiên cứu xây dựng mô hình cung cấp dịch vụ, sản phẩm dữ liệu đo đạc bản đồ trên môi trường mạng sẽ đề xuất mô hình, giải pháp khả thi và triển khai ứng dụng công nghệ GIS trong việc cung cấp dịch vụ, sản phẩm dữ liệu đo đạc bản đồ qua mạng internet, qua đó giúp cho việc cung cấp các dịch vụ, sản phẩm dữ liệu đo đạc bản đồ tới người sử dụng được thực hiện một cách nhanh chóng và hiệu quả.

2. Hiện trạng cung cấp dữ liệu đo đạc bản đồ và các vấn đề tồn tại

\subsection{Hiện trạng}

Trước đây, các dữ liệu đo đạc bản đồ được tổ chức lưu trữ trong kho lưu trữ trên các vật mang tin như CD, DVD. Khi khách hàng có nhu cầu cung cấp dữ liệu, các thông tin chi tiết sẽ được tra cứu trên một phần mềm cài trên máy tính cá nhân. Kết quả tra cứu sẽ được ghi vào phiếu để tìm kiếm trên đĩa $C D$ hoặc DVD và sao chép lại cung cấp cho khách hàng.

Tuy việc quản lý, cung cấp tư liệu đo đạc bản đồ đã được thực hiện bằng phần mềm vận hành nội bộ, nhưng việc giao dịch với khách hàng vẫn còn nhiều điểm chưa thuận lợi, chưa tận dụng được ưu thế về mạng thông tin để quảng bá và phổ biến thông tin tới khách hàng trên quy mô lớn.

\subsection{Các vấn đề tồn tại}

Về mặt quản lý và lưu trữ: Do khối lượng tư liệu đo đạc bản đồ rất lớn nên việc quản lý khá phức tạp. Đa số các địa phương còn quản lý bằng thủ công hoặc quản lý bằng 
các phần mềm vận hành nội bộ chưa đặt vấn đề áp dụng thương mại điện tử trong việc thương mại hóa thông tin sản phẩm dữ liệu đo đạc bản đồ.

Về mặt cung cấp thông tin: Hiện nay khách hàng phải đến tận nơi, liên hệ trực tiếp để tìm thông tin về tình hình dữ liệu khu vực mình cần. Do đó thụ động trong việc quảng bá thông tin đến đại đa số khách hàng.

Hạn chế cơ bản của các hệ thống phần mềm hiện tại:

Các hệ thống hiện tại mới dừng ở mức độ thông báo về biểu giá khai thác tư liệu đo đạc bản đồ;

Chưa cho phép tra cứu thông tin danh mục dữ liệu trực tuyến;

Chưa cung cấp sản phẩm đo đạc bản đồ trên mạng;

Chưa nghiên cứu về khai thác sử dụng dịch vụ đo đạc bản đồ hay các giải pháp giá trị gia tăng trên sản phẩm đo đạc bản đồ;

Chưa ứng dụng thương mại điện tử trong việc cung cấp dịch vụ và sản phẩm dữ liệu đo đạc bản đồ,...

3. Giải pháp xây dựng mô hình cung cấp dịch vụ, sản phẩm đo đạc bản đồ trên môi trường mạng

\subsection{Yêu cầu hệ thống}

Hệ thống cung cấp dịch vụ, sản phẩm đo đạc bản đồ được xây dựng phải đáp ứng được các yêu cầu cơ bản sau đây:

Xây dựng theo mô hình tiên tiến, đảm bảo tính an toàn, bảo mật và hoạt động cung cấp các dịch vụ tra cứu thông tin trực tuyến, liên tục;

Cơ sở dữ liệu tuân theo chuẩn thông tin địa lý cơ sở đảm bảo tính mở và cập nhật thường xuyên;

Cho phép khách hàng tra cứu thông tin một cách nhanh chóng theo thuộc tính và tra cứu theo mô hình không gian;

Cho phép khách hàng thực hiện trả phí khai thác đo đạc bản đồ trên mạng thông qua các dịch vụ internet banking.

\subsection{Mô hình phát triển ứng dụng}

Mô hình kiến trúc ứng dụng được xây dựng theo kiến trúc đa lớp (xem hình 1)

- Tầng cơ sở dữ liệu: Chịu trách nhiệm lưu trữ toàn bộ dữ liệu của Hệ thống. Cơ sở dữ liệu được chia thành các CSDL thành phần sau:

CSDL đo đạc bản đồ chịu trách nhiệm tổ chức, lưu trữ các loại dữ liệu đo đạc bản đồ khác nhau;

CSDL giao dịch chịu trách nhiệm tổ chức, lưu trữ các loại thông tin về khách hàng, đơn hàng và các giao dịch của khách hàng.

Hệ thống CSDL GIS thiết kế và cài đặt trên hệ quản trị dữ liệu Oracle 11g;

- Tầng dịch vụ cơ sở dữ liệu: Lớp dịch vụ dữ liệu đóng vai trò cung cấp các hình thức quản lý, tổ chức dữ liệu địa lý trong CSDL quan hệ. Lớp dịch vụ dữ liệu đước sử dụng các phần mềm midware làm nền tảng để truy xuất dữ liệu và làm cơ sở để các lớp trên tương tác.

- Tầng dịch vụ ứng dụng: Cung cấp các dịch vụ ứng dụng thực hiện các thao tác theo chức năng hệ thống. 


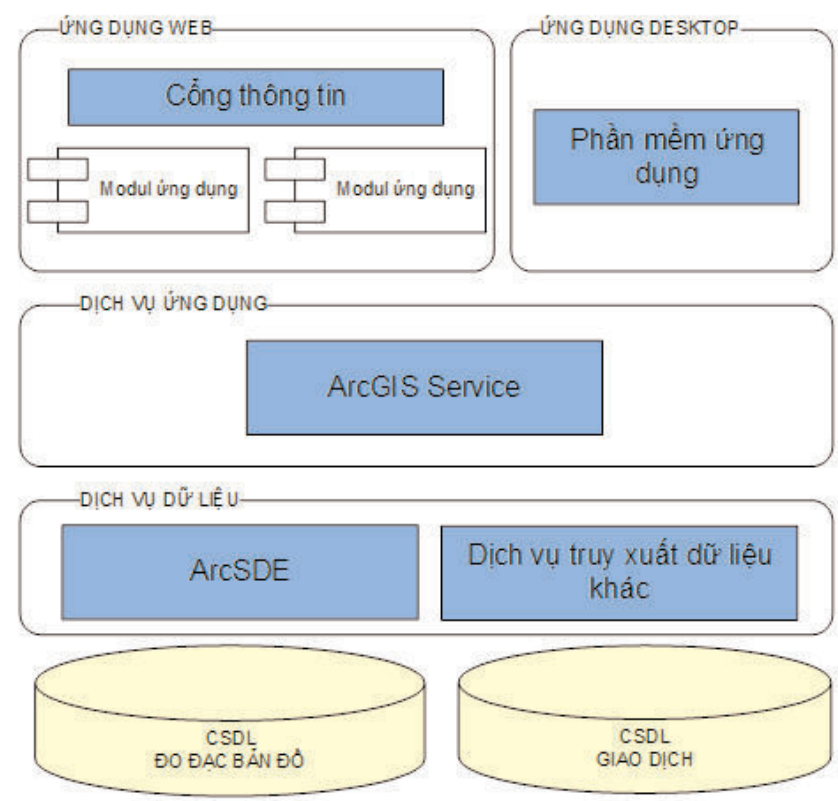

Hình 1: Mô hình kiến trúc hệ thống

- Tầng ứng dụng: Tầng này cài đặt các ứng dụng phần mềm trực tiếp xử lý các chức năng của hệ thống và tương tác với người sử dụng. Tầng này gồm hai thành phần chính là các phần mềm được thực hiện bởi nền tảng ứng dụng web và các phần mềm được thực hiện bởi nền tảng ứng dụng Desktop.

Về tổng thể hệ thống, hệ thống được xây dựng theo cấu trúc hướng dịch vụ SOA (Service Oriented Architecture) bao gồm nhiều lớp. Lớp dưới thực hiện các chức năng cung cấp dịch vụ cho lớp trên. Ưu điểm của cấu trúc $S O A$ trong hệ thống này:

- Đây là một hệ thống tiên tiến được sử dụng nhiều trong các hệ thống tin học hiện đại, có thể xây dựng nhanh chóng và khai thác hiệu quả;

- Linh hoạt trong quá trình sử dụng và chỉnh sửa hệ thống đáp ứng người sử dụng;

- Dễ dàng mở rộng;
Giải pháp phần mềm ứng dụng: sử dụng thư viện ArcEngine, ArcGIS Server của ESRI.

Giải pháp phát triển ứng dụng dựa trên dịch vụ IIS và ngôn ngữ phát triển là ASP.Net của Microsoft.

\subsection{Thanh toán trực tuyến}

Hệ thống cho phép tích hợp với cổng thanh toán điện tử phổ biến nhất ở Việt Nam hiện nay là vnpay.vn. Từ đó hỗ trợ nhận thanh toán bằng thẻ tín dụng hoặc debit ngay trên website. Kết quả thanh toán được phản ánh ngay lập tức vào thông tin đơn hàng khi đặt hàng.

\subsubsection{Quy trình kết nối (xem hình 2)}

\subsubsection{Mô tả quy trình:}

- Khách hàng vào website TMĐT để mua hàng và chọn Thanh toán trực tuyến qua VNPAYMENT để thanh toán đơn hàng. 


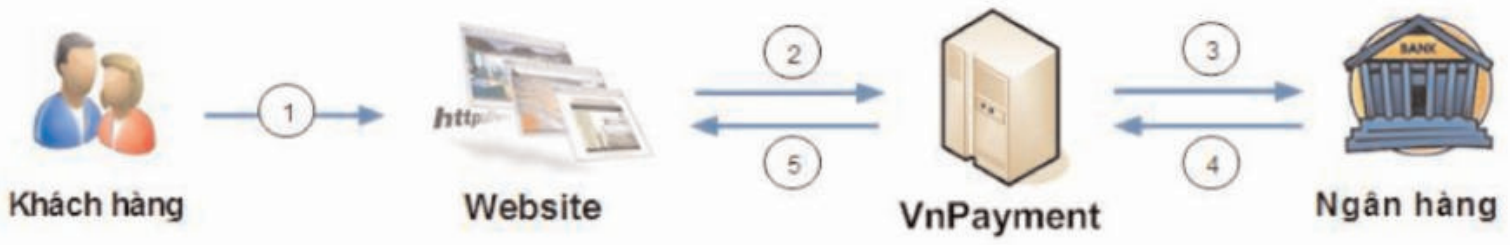

Hình 2: Quy trình kết nối với cổng thanh toán điện tử

- Website TMĐT gửi yêu cầu khởi tạo đơn hàng sang bên VNPAYMENT thông qua webservices.

- VNPAYMENT trả về một địa chỉ URL cho Website TMĐT, Website TMĐT sẽ chuyển khách hàng tới trang VNPAYMENT theo URL này để khách hàng tiếp tục thực hiện việc Thanh toán.

- Khách hàng chọn Phương thức thanh toán (chọn Ngân hàng để thanh toán) tại VNPAYMENT và tiến hành xác thực thông tin Chủ sở hữu tài khoản Ngân hàng tại VNPAYMENT.

- Xác thực thông tin Chủ sở hữu Tài khoản ngân hàng thành công, Khách hàng được chuyển sang Ngân hàng tương ứng để thực hiện phần còn lại của Thanh toán.

- Khách hàng thanh toán đơn hàng xong, VNPAYMENT sẽ gửi thông báo kết quả thực hiện giao dịch cho Website TMĐT và chuyển Khách hàng tới trang thông báo kết quả giao dịch đó.

\subsubsection{Xử lý đơn hàng:}

Căn cứ vào kết quả thực hiện giao dịch mua hàng của khách hàng, Đối tác TMĐT (người bán hàng, chủ sở hữu của website TMĐT) sẽ xử lý đơn hàng căn cứ theo kết quả thực hiện GD của khách hàng:

- Giao dịch thành công: Đối tác TMĐT tiến hành giao hàng cho khách theo đúng yêu cầu của đơn hàng.

- Giao dịch thành công tại VNPAYMENT - Hết hàng: Đối tác TMĐT sẽ đăng nhập vào VNPAYMENT và hoàn tiền lại cho khách hàng.

- Giao dịch không thành công: Căn cứ vào mã lỗi trả về của VNPAYMENT, website TMĐT sẽ hiển thị thông báo lỗi cho khách hàng biết

\section{Kết quả đạt được}

Các hệ thống phần mềm sản phẩm của đề tài đã được vận hành thử nghiệm trong thời gian thực hiện đề tài với các khách hàng khác nhau. Cụ thể bao gồm các phần mềm sau:

- Website thương mại điện tử đo đạc và bản đồ: cho phép khách hàng có thể duyệt, tra cứu sản phẩm đo đạc và bản đồ, đặt hàng sản phẩm, giao dịch với Cục Đo đạc và Bản đồ Việt Nam qua các hệ thống đặt hàng được tích hợp trong phần mềm, cho phép cán bộ Cục Đo đạc và Bản đồ Việt Nam có thể quản lý được danh sách khách hàng, quản lý được các đơn hàng và giao dịch sản phẩm. Dễ dàng triển khai tới các nhóm khách hàng khác nhau;

- Phần mềm hỗ trợ tác nghiệp cho cán bộ Cục Đo đạc và Bản đồ Việt Nam trước khi cung cấp sản phẩm đo đạc và bản đồ tới khách hàng: cung cấp các công cụ chuyển 
đổi dữ liệu, tích hợp dữ liệu mới vào trong hệ thống.

Trong quá trình thử nghiệm, hệ thống vận hành ổn định cho thấy có thể triển khai trong công tác khai thác và cung cấp sản phẩm đo đạc và bản đồ của cơ sở dữ liệu đo đạc bản đồ trên mạng internet để cung cấp dữ liệu đo đạc bản đồ một cách có hiệu quả.

\section{Kết luận}

Kết quả nghiên cứu và xây dựng mô hình cung cấp dịch vụ, sản phẩm trên môi trường mạng internet, ứng dụng công nghệ GIS và thương mại điện tử đã giải quyết được các hạn chế của hệ thống hiện tại:

Cho phép tìm kiếm, tra cứu danh mục trực tuyến

Cho phép đặt hàng tư liệu đo đạc và bản đồ trên mạng internet

Cho phép thanh toán trực tuyến phí khai thác thông tin tư liệu đo đạc và bản đồ thông qua cổng thanh toán.

Giúp khách hàng tiết kiệm thời gian và chi phí đi lại.
Kết quả nghiên cứu đã nâng cao công tác quản lý và cung cấp sản phẩm đo đạc bản đồ đáp ứng dịch vụ công mức độ 4 . Quá trình vận hành thử nghiệm hệ thống với kết quả khả quan đã khằng định tính khả thi của hệ thống đã đề xuất trong điều kiện công nghệ nước ta. $O$

\section{Tài liệu tham khảo}

[1]. Các tài liệu kỹ thuật của dự án "Xây dựng cơ sở dữ liệu quốc gia về tài nguyên và môi trường", Cục Công nghệ Thông tin.

[2]. Các tài liệu kỹ thuật của dự án "Xây dựng hệ thống quản lý cơ' sở dữ liệu nền địa lý quốc gia và cơ sở dữ liệu đo đạc bản đồ", Cục Đo đạc và Bản đồ Việt Nam.

[3]. Jeffrey A.Hoffer - Mary B.Prescott Fred R. McFaddaen (2010), "Modern Database management (10th Edition)", The benjamin/Cummings Publish Company, Inc.

[4]. Michael Zeiler (2010), "Modeling Our World: The ESRI Guide to Geodatabase Concepts", Environmental Systems Research Institute, Inc

[5]. ESRI Press (2004), "ArcG/S Engine Developer's Guide". O

\section{Summary}

\section{Study and build the model for delivery products of survey and mapping in net- work}

MSc. Nguyen Van Tuan

Department of Survey and Mapping Vietnam

The article describes the results of studies on the supply of data is being done at the Department of Survey and Mapping Vietnam. Proposed and build a system for delivery products of survey and mapping through the Internet, allowing users to access data quickly and more convenient. $O$ 